\title{
PRODUCING OF BIMETAL JOINTS BY LASER WELDING WITH FULL PENETRATION
}

\author{
M. SCHMIDT ${ }^{1}$ and S.V. KURYNTSEV ${ }^{2}$ \\ ${ }^{1}$ Fridrich-Aleksandr University, Erlangen, Germany \\ ${ }^{2}$ A.N. Tupolev Kazan National Research Technical University \\ 10 K. Marks Str., Kazan, 420111, RF. E-mail: kuryntsev16@mail.ru
}

\begin{abstract}
Current level of development of technologies for treatment of metallic materials is impossible without using of lasers, which have found application in such processes as cutting, heat treatment, welding, engraving and brazing. This paper describes investigation of process of production of stainless steel-brass bimetal joint using laser welding with full penetration. The specimens were welded on equipment of IPG «IRE-Polus» Ltd. This company manufactures machines for laser welding using tongs. Thickness of specimens from $12 \mathrm{Kh} 18 \mathrm{~N} 10 \mathrm{~T}$ steel and L63 brass made $3 \mathrm{~mm}$. Welding was carried out at different modes, and influence of postweld heat treatment on mechanical properties of the joints was evaluated. Performed are metallographic investigations, and microhardness of different zones of welded joint is measured. It is determined that application of laser welding with full penetration for production of bimetal joints is possible under condition of more accurate adjustment of welding modes and postweld heat treatment. 8 Ref., 2 Tables, 6 Figures.
\end{abstract}

Keywords: laser welding, tongs, full penetration weld, bimetal joint, microhardness, metallography

Application of composite metallic materials, in particular bimetals, allows combining valuable service and physical-mechanical properties, typical for dissimilar metals, such as corrosion resistance and mechanical strength, tribotechnical characteristics and corrosion resistance, tribotechnical characteristics, heat resistance, and high-temperature strength in one product. Bimetals find wide application in machine-, ship-, aircraft building, chemical industry and production of power installations.

Joining of some pairs of metals by fusion welding is impossible since they are metallurgically incompatible or due to formation in a fusion line of intermetallics, which have negative effect on mechanical and electrophysical properties of the joints.

There are number of methods for production of bimetals, in particular, pouring of molten metal on moving steel strand, metallic powder sintering, arc surfacing [1, 2], magnetic-pulse welding, roll welding [3], explosion welding [4], linear friction welding, ultrasonic welding and diffusion welding [5]. All this methods have a series of technological disadvantages, namely complexity of manufacture, low indices of process ecological compatibility, maximum efficiency only in bulk production, high energy intensity of the processes, low productivity, narrow specializing of used equipment, labouriousness and irregular repeatability of the technological process. Therefore, implementation into commercial production of more advanced technologies providing high indices of energy efficiency, repeatability of the technological process, automation and robotization of the technology is relevant. At present time, laser technologies are state-of-the-art in the world practice and fulfill current requirements.

At the same time, the disadvantages, typical for laser technologies, can be outlined. Among them is an insufficiently studied mechanism of formation of vapour-gas channel due to the fact that generation of pores in the welded joints is connected with it. Works [6, 7] study the issue of groove preparation for gas-shielded welding. Work [8] proposes a technology of laser-arc hybrid welding with full penetration and represents the results of influence of surface pre-treatment, level of pressing of semi-products to each other, modes of hybrid process, fluxes, shielding gases and filler wire on joint formation and thermal cycle of welding.

The present paper considers application of laser welding with the help tongs for production of bimetal semi-products as an alternative to widely used methods.

Laser welding using tongs is the process of production of permanent joint by means of creation of interatomic bonds between two or more flat semi-products. As a result of influence of laser beam, traveling on specific trajectory, on a surface of one of semi-products, a joint is formed due to remelting of boundaries of two surfaces, 
Table 1. Modes of production of $12 \mathrm{Kh} 18 \mathrm{~N} 10 \mathrm{~T}$ steel $+\mathrm{L} 63$ brass specimens

\begin{tabular}{||c|c|c|}
\hline \hline Mode & $N, \mathrm{kV}$ & $v_{\mathrm{w}}, \mathrm{mm} / \mathrm{s}$ \\
\hline 1 & 3.0 & 25 \\
\hline 2 & 2.5 & 25 \\
\hline 3 & 2.5 & 15 \\
\hline
\end{tabular}

possibly with complete and incomplete penetration (Figure 1). The welding technology is the following. The semi-products to be welded are placed between clamping collets of the tongs (Figure 1,b) that provides sufficiently tight pressing. A shielding gas is fed into the hollow tongs and a laser beam is directed, virtually, simultaneously normal to the semi-products being welded through the upper collet clamp.

Below are given the characteristics of laser welding process with full penetration:

Weight of tongs, $\mathrm{kg}$ 45

Pressing force, $\mathrm{kN}$ $0.6-0.3$

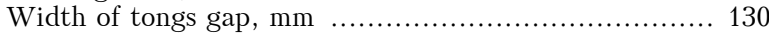

Length of welding zone, $\mathrm{mm}$.................................. $0-40$

Amplitude of beam oscillation, $\mathrm{mm}$......................... 2

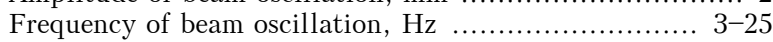

Welding speed, $\mathrm{mm} / \mathrm{s}$............................... max 80

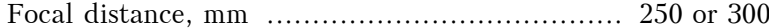

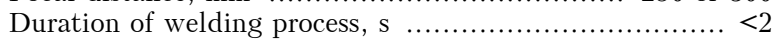

The main advantages of laser welding using tongs are the following: possibility of production of welded joints from dissimilar metals, high
Table 2. Influence of heat treatment mode on microhardness of section of L63 brass partially mixed with $12 \mathrm{Kh} 18 \mathrm{~N} 10 \mathrm{~T}$ steel

\begin{tabular}{|c|c|c|c|}
\hline \hline Mode & $T,{ }^{\circ} \mathrm{C}$ & $t, \mathrm{~h}$ & $H V 0.5, \mathrm{MPa}$ \\
\hline 1 & 400 & 1.3 & $950-1030$ \\
\hline 2 & 350 & 3.0 & $870-940$ \\
\hline 3 & 500 & 3.0 & $850-890$ \\
\hline
\end{tabular}

welding speed, short-time heating, and as a result, virtually, complete absence of HAZ, possibility of automation and robotization of the technological process. Application of program control for laser equipment and adjusted technology can provide high index of repeatability of the welding process, that is very important under conditions of serial production. Commercial implementation of laser complexes of «IRE-Polus» requires no fundamental changes in the technological process of welding, the equipment is sufficiently compact, consumed energy is comparable with the competitive technologies.

Nature of this process, for production of bimetals, lies in performance of joint of two or more homogeneous or dissimilar metal sheets, positioned over each other, by full penetration welds. The laser beam is traveled along the specific trajectory (Figure 2, $a$; weld - in the specimen center) in order to increase joint area. Series of specimens from 12Kh18N10T steel + L63 brass with incomplete penetration was prepared and

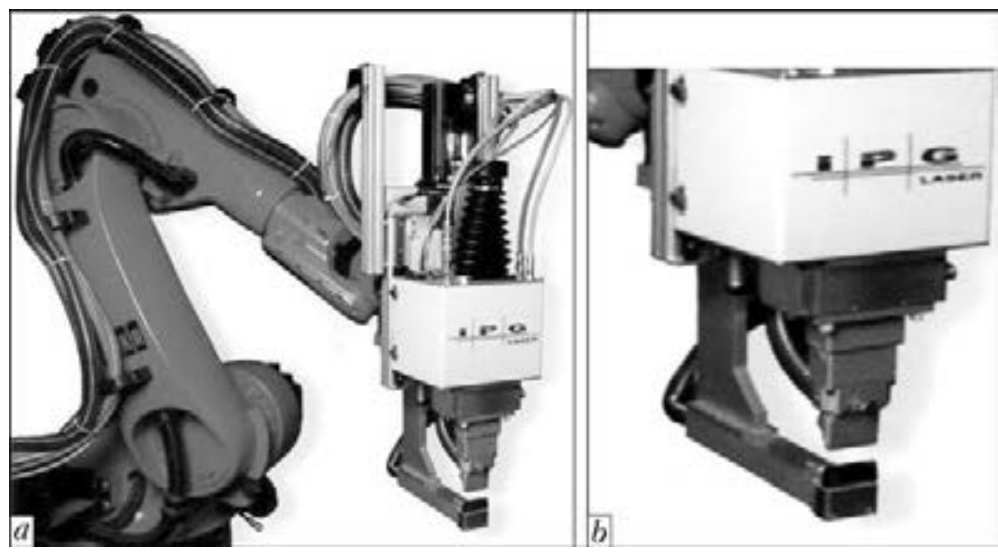

Figure 1. Appearance of machine for laser welding with LSS tongs $(a)$ and collet $(b)$

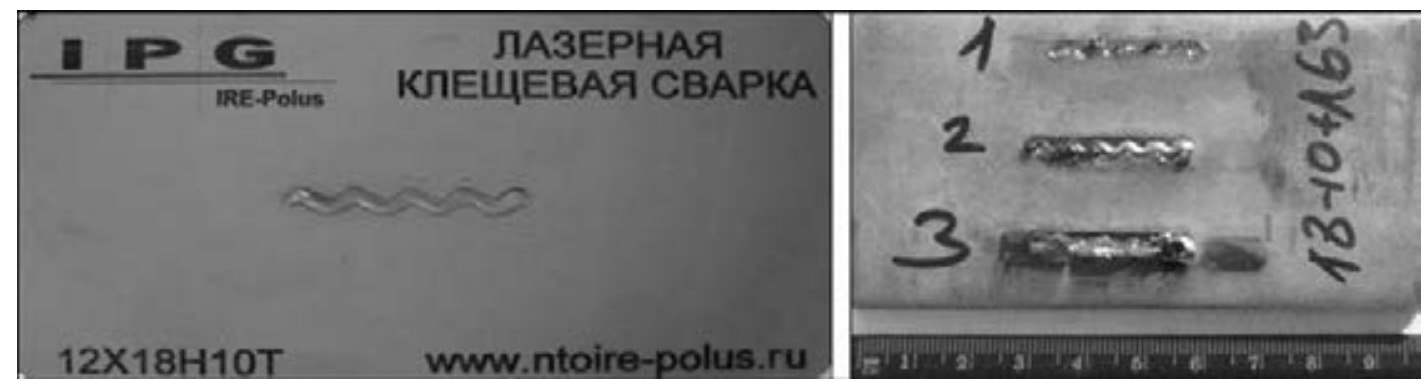

Figure 2. Laser-welded specimens: $a$ - welded joint of 12Kh18N10T $+12 \mathrm{Kh} 18 \mathrm{~N} 10 \mathrm{~T}$, one mode; $b-$ welded joint of 12Kh18N10T + L63, three modes 

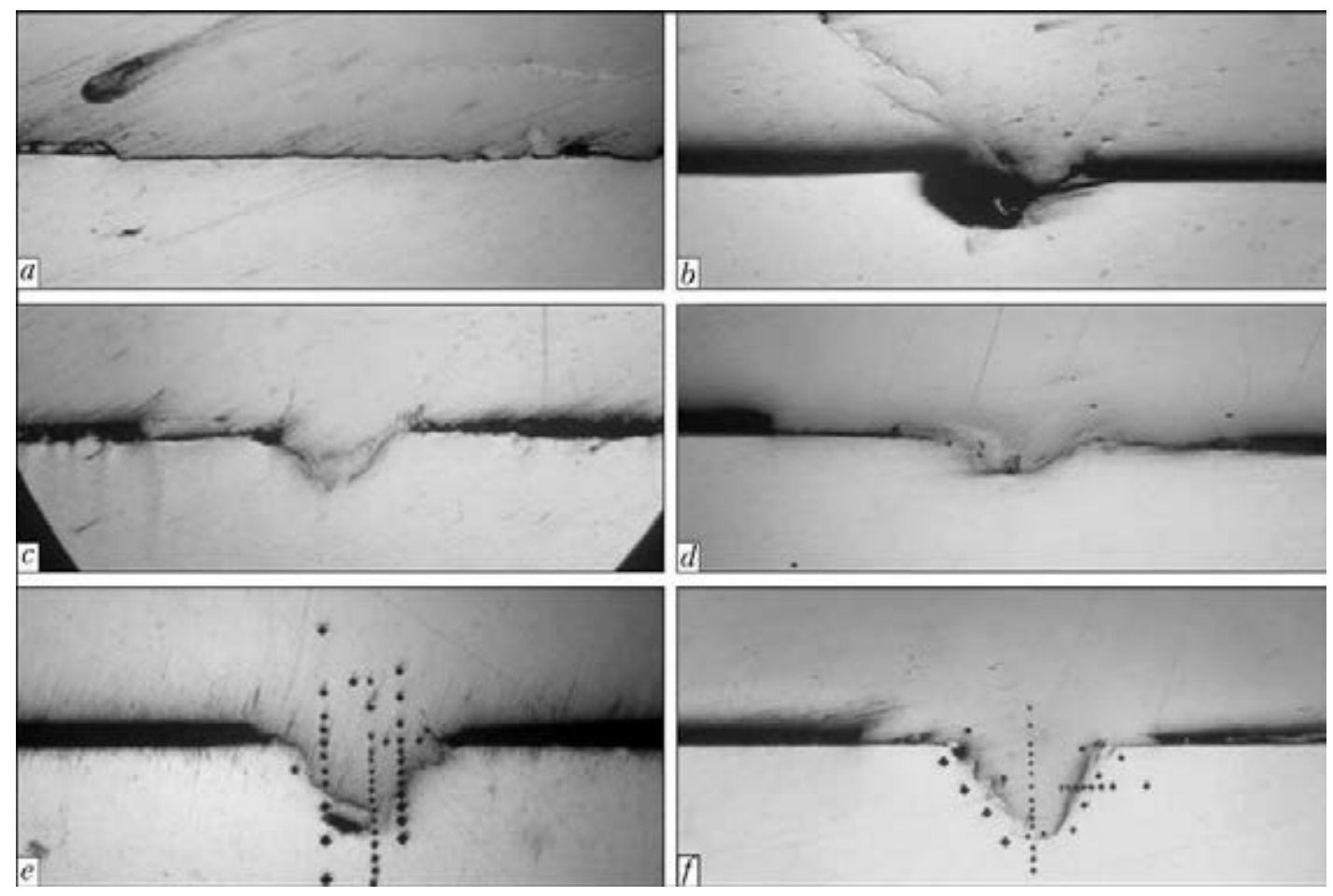

Figure 3. Transverse macrosection $(\times 100)$ of welded joint: $a$ - section 1 , depth $1 \mathrm{~mm} ; b-$ section 2 , depth $3 \mathrm{~mm} ; c-$ section 3, depth $4.5 \mathrm{~mm} ; d$ - section 4 , depth $6 \mathrm{~mm}, e$ - section 5 , depth $7.5 \mathrm{~mm} ; f$ - section 6 , depth $9.5 \mathrm{~mm}$

welded for investigation of mechanism of joint formation. Thickness of 12Kh18N10T and L63 plates made $3 \mathrm{~mm}$. The laser beam traveled along the specific trajectory on surface of steel, the specimens were welded at different modes $\left(\mathrm{Ta}^{-}\right.$ ble 1). Aging of the specimens with penetration at different modes (Table 2) was carried out after welding for determination of effect of heat treatment on mechanical properties of the joint.

Metallographic investigations were carried out using the Carl Zeiss optic microscope Axiovert 200, microhardness of the layers, fusion zones and HAZ were measured on the Remet microhardness tester HX 1000.

It was found during metallographic investigations that penetration at all modes is not constant (Figure 3). Photos of several layers of the one filled microsection were made. Specific layer of 1.5-2.0 mm thickness was removed after each investigation using grinding and polishing, photographing and investigation of the mechanical properties were repeated. The joint is inhomogeneous as can be seen from the presented photos of different on depth section of the one specimen. Metallographic investigations also showed that the sections of joint formation have an interlayer in form of solidified mechanical mixture from steel and brass. The values of microhardness have insignificant difference for these sections.

Figure 4 shows the microstructure of joints with indentations, area of large indentations in the left part of the photo (Figure 4, $a$ ) was made at $H V 1$ load. However, as it was necessary to determine sufficiently narrow transition zones,

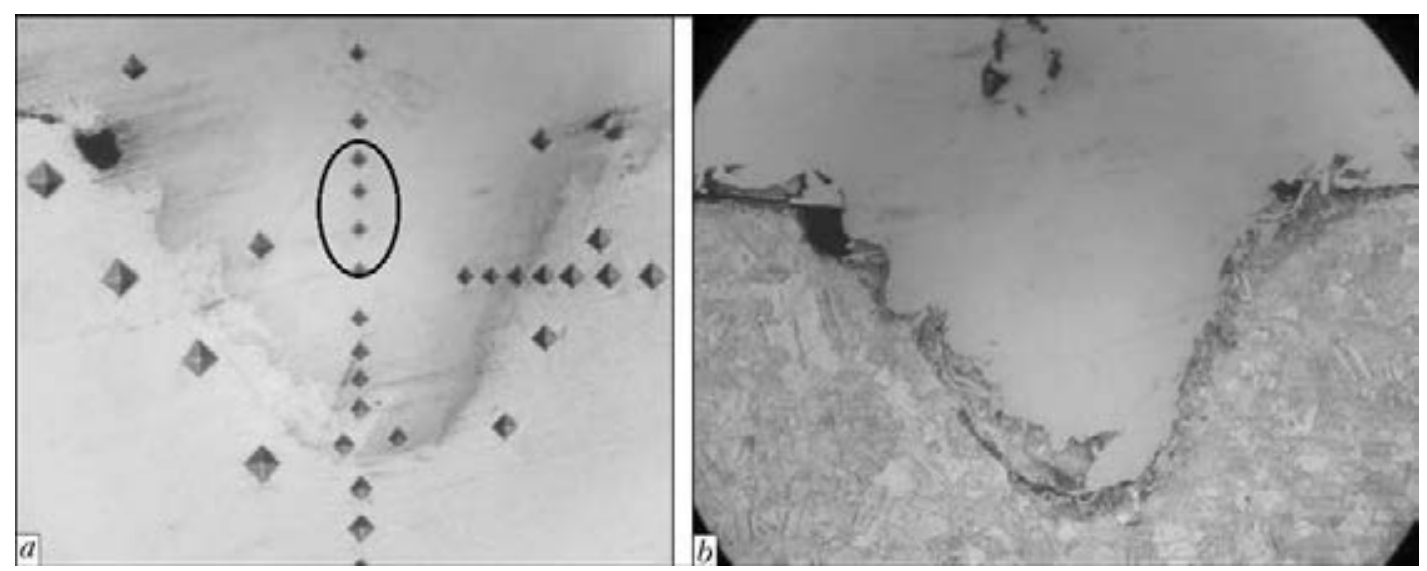

Figure 4. Macrosection $(\times 250)$ of one section of welded joint with incomplete penetration after measuring of microhardness (a) and etching $(b)(12 \mathrm{Kh} 18 \mathrm{~N} 10 \mathrm{~T}$ - in the upper part, L63 - in the lower) 


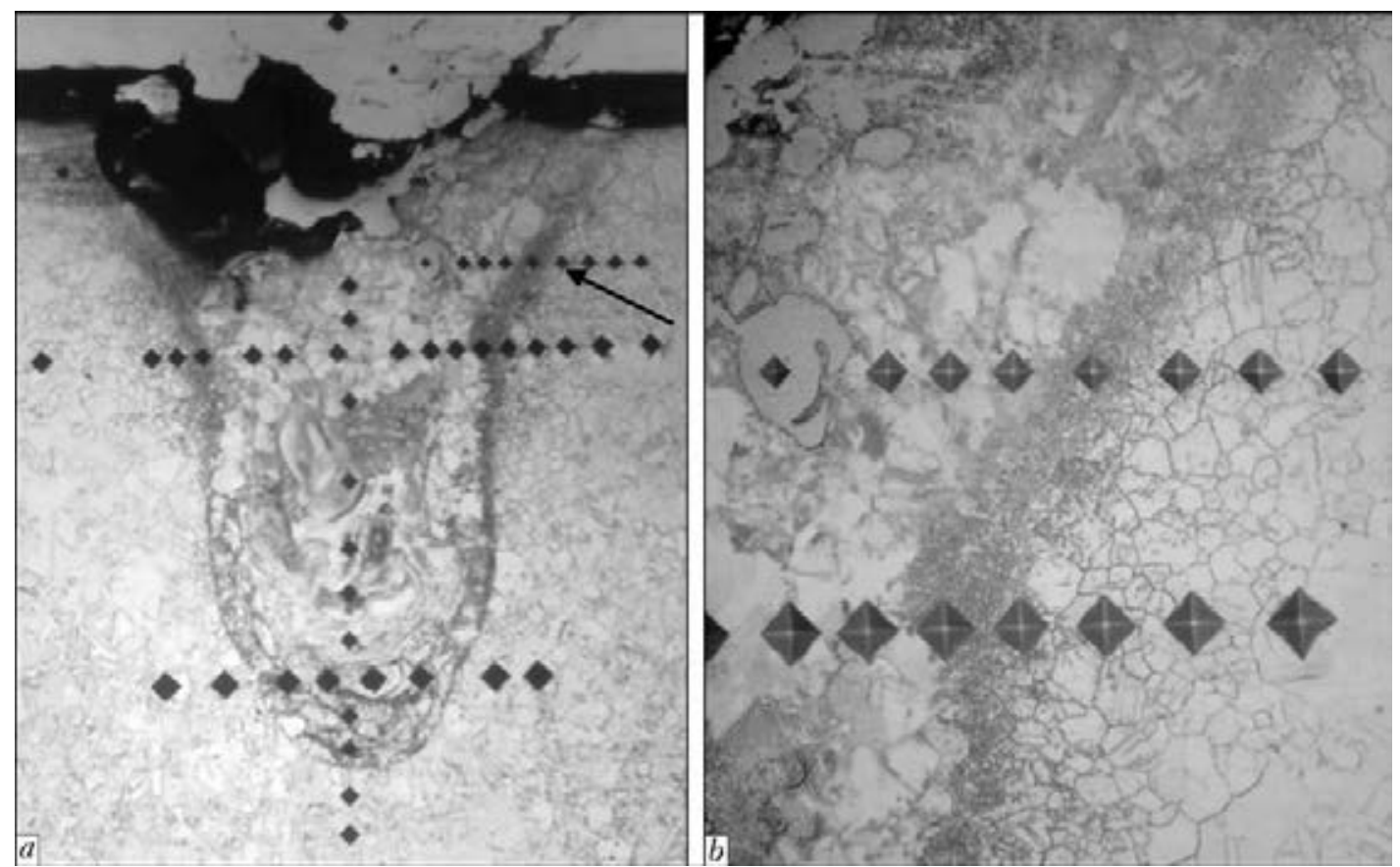

Figure 5. Macrosection of welded joint with minimum penetration: $a-$ general appearance, brass $(\times 250) ; b-$ fusion area $(\times 800)$
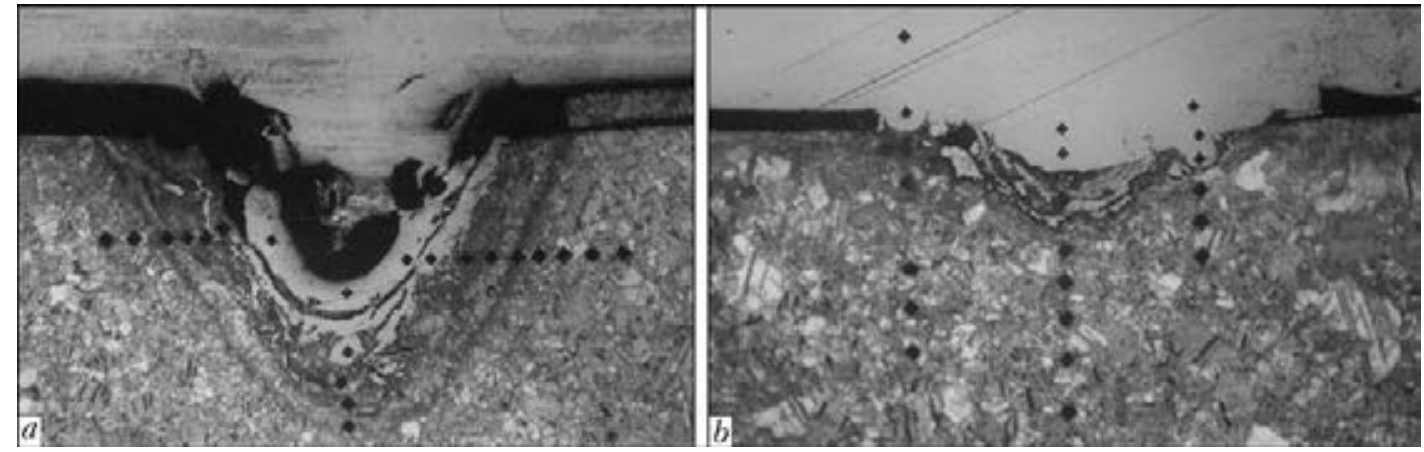

Figure 6. Macrosection $(\times 100)$ of welded joints after heat treatment at modes $1(a)$ and $2(b)$

and alloys have relatively low hardness values, the basic measurements were carried out at $H V 0.5$ load. Fusion lines, defects in form of pores, structural changes after laser beam thermal influence are clearly seen in the photos before and after etching. Microhardness of different sections of steel after laser influence is in $H V 1^{-}$ 1700-2500 MPa range, at that the maximum values are represented in the central part of the photo (Figure 4, $a$ ). Brass-steel fusion line is in HV1-1050-1750 MPa range, brass base metal has HV1-870-1050 MPa.

Figure 5, $a$, presenting a microsection of the specimen without heat treatment, clearly depicts depth of penetration by laser beam, steel to brass fusion line is virtually absent. Figure $5, b$ shows structural changes in the fusion line, laser-affected base metal and brass sections with steel inclusion. Microhardness in Figure 5, $b$ was measured at $H V 0.25$ (upper line of indentations) and $H V 0.5$ (lower line). It can be seen that using of lower loading allowed measuring exactly the val- ues for fusion line, where microhardness of brass is comparable with steel values and lies in $H V 1^{-}$ 1500-1700 MPa range.

Macrosections of specimen with small fusion section, subjected to heat treatment by modes 1 and 2 (Table 2), are represented in Figure 6, $a$ and $b$. Heat treatment of given joints was carried out for the purpose of mutual diffusion of alloy components in order to increase joint strength. It can be seen in the photos that heat treatment provoked balancing of the structure, values of microhardness of this brass section have no rapid drops in comparison with the specimens, which are not subjected to heat treatment. However, expected increase of joint strength due to mutual diffusion was not registered.

\section{Conclusions}

1. Laser welding with full penetration can be considered as a promising method of production of bimetal joints, since the process can be auto- 
mated and allows joining metals of different combinations in a wide range of thicknesses.

2. Mechanical properties of the joints after welding are inhomogeneous, therefore, heat treatment can be used for their balancing, if necessary.

The work was carried out with support of the grant of the Ministry of Education and Science of $R F$ in scope of decree No.220, application No. 14z50.31.0023.

1. Bely, A.I. (2010) Influence of main technological parameters of the plasma cladding process on properties of composite deposited metal. The Paton Welding J., 6, 25-27.

2. Ryabtsev, I.A., Kondratiev, I.A., Vasiliev, G.V. et al. (2010) Investigation of structure and service properties of deposited metal for reconditioning and strengthening of rolling mill rolls. Ibid., 7, 12-15.
3. Neklyudov, I.M., Borts, B.V., Lopata, A.T. et al. (2010) Development of zirconium- and stainless steelbased composites for manufacture of adapters to NPP structures. Ibid., 8, 45-49.

4. Shlensky, P.S., Dobrushin, L.D., Fadeenko, Yu.I. et al. (2011) Chambers for explosion welding of metals (Review). Ibid., 5, 47-51.

5. Lyushinsky, A.V. (2011) Application of nanopowders of metals in diffusion welding of dissimilar materials. Ibid., 5, 31-34.

6. Sokolov, M., Salminen, A. (2013) Laser welding of low alloyed steels: Influence of edge preparation. Ibid., 2, 48-52.

7. Quiroz, V., Gumenyuk, A., Rethmeier, M. (2012) Investigations on laser beam welding of high-manganese austenitic and austenitic-ferritic stainless steels. Ibid., 1, 10-14.

8. Khaskin, V.Yu. (2011) Laser welding of overlap joints of low-carbon steels by through-thickness welds. Svarshchik, 5, 24-26.

Received 11.12.2013 